\section{A denture partner}

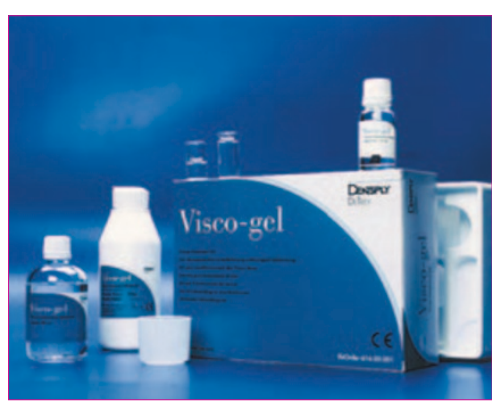

Visco-gel from DENTSPLY is a tissue conditioner and temporary soft denture liner complying with international standards for resilient lining materials for removable dentures

Visco-gel is available as powder/liquid and its consistency can be easily adapted if required. Due to its long working time, it allows all adaptations to be made in the patient's mouth and the excess material can be easily removed.

As well as its uses as a tissue conditioner and temporary soft liner, Visco-gel can also be used as a functional impression material in post-operative cases or when ill-fitting dentures require replacement or rebasing. For more information contact 01932837235 or email alpana.vijayaraghavan@dentsply-gb.com

\section{Online service for students}

\section{L $\widetilde{\odot}$ king for Dental.com}

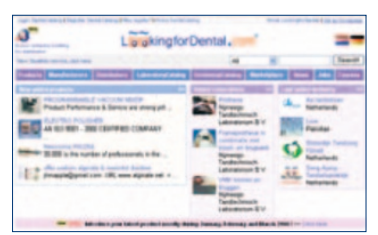

Looking For Dental have announced a new free service for students. Developed in association with a college for dental technicians, the new system aims to bring employers and jobseekers together by allowing students to present themselves online on a worldwide dental portal. By using their personal login, they are then able to introduce themselves to potential employers by completing an online profile, with information including any areas of specialism and the type of work they are looking for. There is also the ability to include a photograph of their best piece of work and to indicate if they are searching for equipment, for example, by using the site's marketplace feature.

Building on existing services for manufacturers, distributors, dental laboratories and dentists, the service will be available for use by all dental technicians and dental students worldwide from the beginning of April 2006.

For more information please contact Hans Dijk at Looking For Dental on +31 653870071 or email hans@lookingfordental.com

\section{Sanitary syringe tips}

The SaniTip ${ }^{\circledR}$ disposable syringe tip system effectively reduces cross-contamination whilst ensuring dry air at every use.

\section{metal air-and-water}

syringes supplied with most

dental chairs often suffer from the

quick build-up of biofilms and with such

narrow lumens, they may be difficult to sterilise sufficiently between patients, and air and water separation cannot be guaranteed. This problem can worsen over time, putting the success of restorations at risk.

SaniTip ${ }^{\circledR}$ offers a simple solution to this problem, as it is disposable with excellent air and water separation. Adapters are available to fit practically every dental syringe and are free of charge. For more information, please contact DENTSPLY on 01932853422.
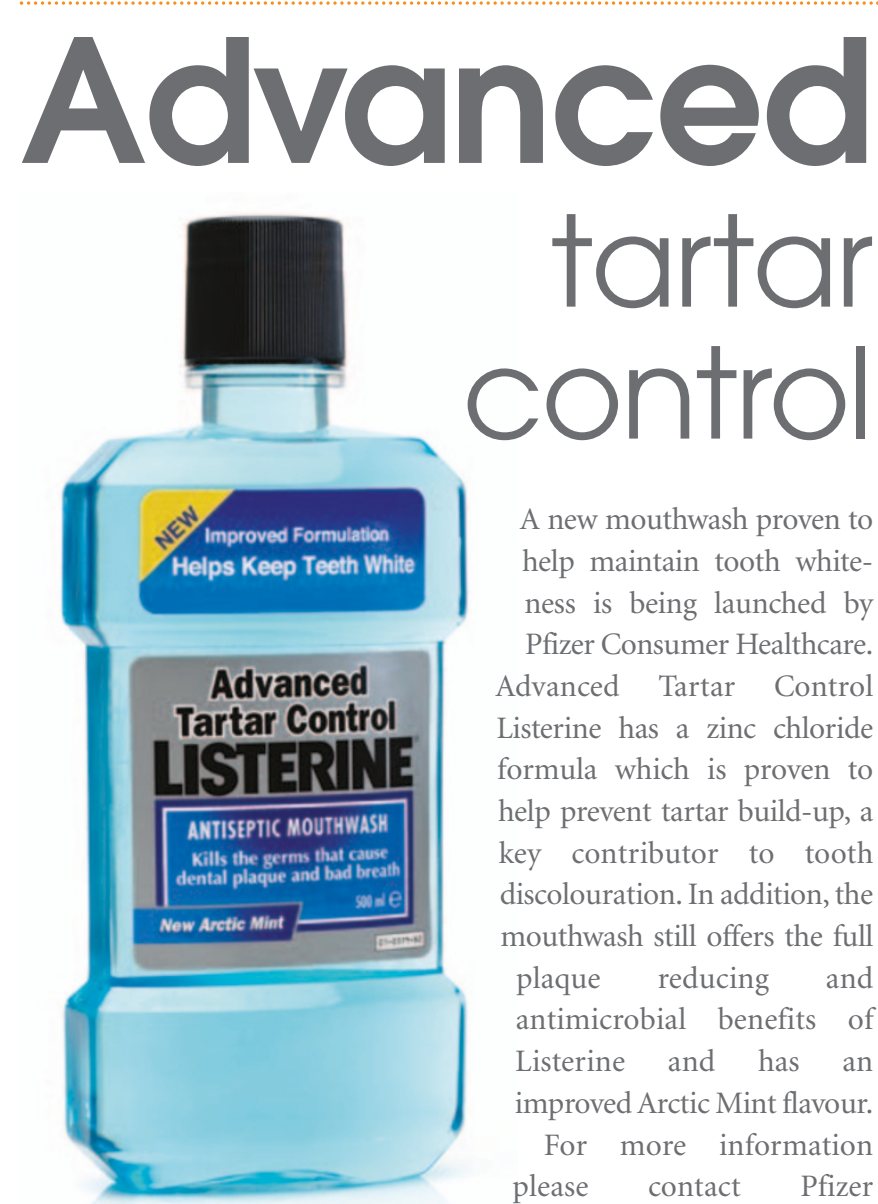
control

A new mouthwash proven to help maintain tooth whiteness is being launched by Pfizer Consumer Healthcare. Advanced Tartar Control Listerine has a zinc chloride formula which is proven to help prevent tartar build-up, a key contributor to tooth discolouration. In addition, the mouthwash still offers the full plaque reducing and antimicrobial benefits of Listerine and has an improved Arctic Mint flavour.

For more information please contact Pfizer Consumer Healthcare on 01304616161. 